\title{
Relationship of moderate and low isometric lumbar extension through architectural and muscular activity variables: a cross sectional study
}

\author{
Antonio I Cuesta-Vargas ${ }^{1,2^{*}}$ and Manuel Gonzalez-Sanchez ${ }^{2}$
}

\begin{abstract}
Background: No study relating the changes obtained in the architecture of erector spinae (ES) muscle were registered with ultrasound and different intensities of muscle contraction recorded by surface EMG (electromyography) on the ES muscle was found. The aim of this study was analyse the relationship in the response of the ES muscle during isometric moderate and light lumbar isometric extension considering architecture and functional muscle variables.

Methods: Cross-sectional study. 46 subjects (52\% men) with a group mean age of 30.4 ( \pm 7.78$)$. The participants developed isometric lumbar extension while performing moderate and low isometric trunk and hip extension in a sitting position with hips flexed 90 degrees and the lumbar spine in neutral position. During these measurements, electromyography recordings and ultrasound images were taken bilaterally. Bilaterally pennation angle, muscle thickness, torque and muscle activation were measured. This study was developed at the human movement analysis laboratory of the Health Science Faculty of the University of Malaga (Spain).

Results: Strong and moderate correlations were found at moderate and low intensities contraction between the variable of the same intensity, with correlation values ranging from 0.726 (Torque Moderate - EMG Left Moderate) to 0.923 (Angle Left Light - Angle Right Light) $(p<0.001$ ). This correlation is observed between the variables that describe the same intensity of contraction, showing a poor correlation between variables of different intensities.

Conclusion: There is a strong relationship between architecture and function variables of ES muscle when describe an isometric lumbar extension at light or moderate intensity.
\end{abstract}

Keywords: Ultrasonography, Surface electromyography, Thickness, Pennation angle, Erector spinae

\section{Background}

An in-depth study of the behaviour of musculoskeletal structures allows access to a wealth of information that could be very useful for understanding the response of these structures to different situations or stimuli $[1,2]$. To that end, many studies have resorted to investigating architectural and functional variables in isolation [3-7] and integrating both types of variable [8-10]. Muscle fibre pennation angle (defined as the angle that creates muscle fibers with respect to the muscular aponeurosis [11]) and muscle thickness (defined as the shortest

\footnotetext{
* Correspondence: acuesta@uma.es

${ }^{1}$ School of Clinical Sciences, Faculty of Health, Queensland University of Technology (QUT), Victoria Park Road, Kelvin Grove QLD 4059, Australia

${ }^{2}$ Department of Physiotherapy, Faculty of Health Sciences, University of Malaga, 29071, Málaga, Spain
}

distance between surface and deep aponeurosis of muscle [11]) are two variables of muscle architecture, which have been utilised in various studies as indicators of the force generated by the muscle during contraction $[10,12]$. Many studies have been published in which at least one of these two variables was considered to describe muscle behaviour after a given stimulus [8-10,12-14], but the relationship between ultrasonographic and electromyographic variables is somewhat controversial. Some studies have shown a strong relationship between them, while others have found a low ratio $[8-10,12]$.

In the field of biomechanics, US (ultrasound) has become a widely used tool to describe changes in muscular architecture produced during muscle contraction [4,14-16]. In recent years, several studies have been published using 
ultrasound to examine the changes in the muscle ES (erector spinae) in different situations $[7,8]$.

In addition, surface electromyography has been used in different studies related to both muscle strength and muscle activation levels [14,17-19]. Some studies have made use of surface electromyography to analyse the level of activation of the paraspinal musculature with different types of contraction $[17,18]$. Its ease of use has allowed it to be a widely used tool in research and with great potential in clinical practice.

No study relating the changes obtained in the architecture of ES muscle were registered with ultrasound and different intensities of muscle contraction recorded by surface EMG (electromyography) on the ES muscle was found. It is important to study the activation together with the contraction (architectural variables) of the ES muscle for several reasons: the anatomical characteristics of the ES are clinically important in patients with LBP (low back pain), since it is actuated and inserted into the lumbar spine [20-22]. In addition, ES muscle is a tonic muscle $[20,21]$. The average intensity of contraction is usually moderate or light, necessary to maintain an upright posture and to assist the movement of lateral flexion, rotation and lumbar extension [23]. This study chased two objectives. To describe the response of the ES muscle during maximal, moderate and light isometric contraction, analysing architecture and function variables, obtained by ultrasound and surface electromyography. The second is to analyse analyse the relationship between architecture and functional variables during moderate and light contractions of the ES muscle using normalized values from MVC.

Our hypothesis was that there is a significant relationship in the response generated by the ES muscle during moderate and light isometric trunk and hip extension in a sitting position with hips flexed 90 degrees and the lumbar spine in neutral position between the seven variables (muscle activation (EMG), muscle thickness and pennation angle (right and left side) and torque) studied in the three contraction intensities.

\section{Methods}

\section{Design}

Cross-sectional study. The independent variable was percentage of maximal extensor force and dependent variables were level of muscle activation, ES thickness and pennation angle.

\section{Participants}

46 subjects ( $52 \%$ men) with a group mean age of 30.4 $( \pm 7.78)$ participated in this study. In this trial, muscle activation (measured with surface electromyography) and architecture variables of the ES muscle (obtained with ultrasound) were measured during isometric lumbar extension while performing moderate and light isometric trunk and hip extension in a sitting position with hips flexed 90 degrees and the lumbar spine in neutral position (Figure 1). This study was developed at the human movement analysis laboratory of the Health Science Faculty of the University of Malaga (Spain). Ethics approval was attained from the ethics committee of the University of Malaga and all subjects gave informed consent following the guidelines of the Helsinki Declaration of 1964 which sets out ethical principles for all human inquiry and has been upgraded in successive meetings of the World Medical Association [24].

\section{Procedure}

During the test, all participants wore sneakers and the foot was supported on a platform. The dynamometer was adjusted so that the axis of rotation was at the height of $L_{5}-S_{1}$. The hip and thigh were fixed to the chair using belts, so that movement of the thigh was minimised. The knee and the hip were $90^{\circ}$ flexed to reduce the tension supported by the hamstring muscles (Figure 1).

\section{Maximal isometric force registration}

Maximum isometric force was recorded by a load cell (RealPower, Globus, Italy), which was located between two chains. One chain was fixated to the wall and the other to the measurement apparatus (Figure 1). The subject developed an isometric contraction at 45 grades from the vertical (Figure 1).

\section{Electromyography}

Two bipolar surface electromyography electrodes (Datalog Biometrics, England; amplifier bandwidth: $20-450 \mathrm{~Hz}$, common mode rejection ratio: $60 \mathrm{~Hz}(\mathrm{~dB})>96$, typically $110 \mathrm{~dB}$; input impedance 1015 Ohms; sampling frequency: $1000 \mathrm{~Hz}$ ) with an inter-electrode distance of

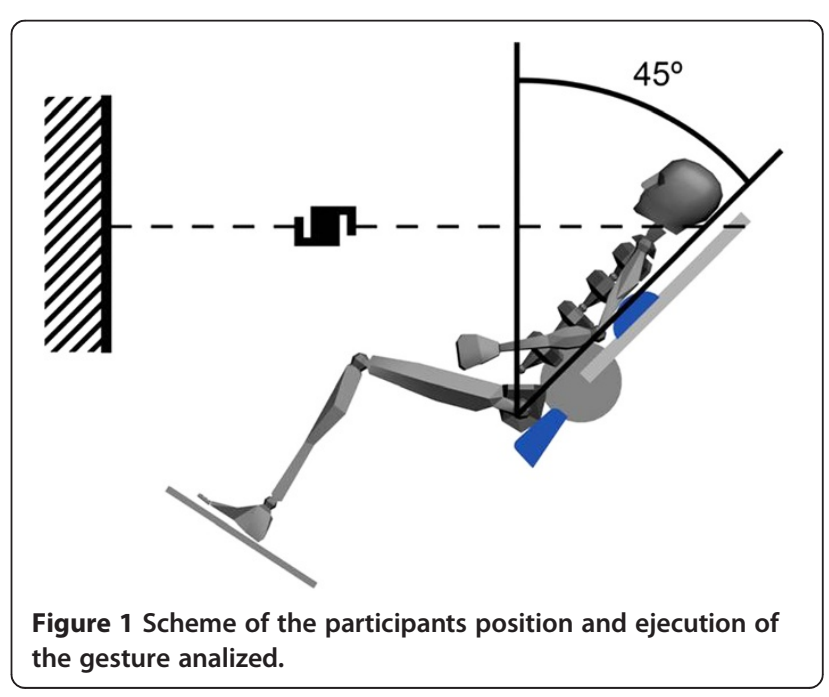


one centimetre were place on the skin surface $3 \mathrm{~cm}$ lateral from the spinous process of $\mathrm{L}_{3}-\mathrm{L}_{4}$. Electromyographic value was taken from the difference between the maximum and minimum registration. Prior to this calculation, all recorded signals were passed $20 \mathrm{HZ}$ low pass Butterworth filter to remove high-frequency noise from the sample. Datalink software 3.0 managed the process of acquisition of values and treatment records.

\section{Ultrasound registration}

The SonoSite Mod Titan ultrasound system was used in this study. It has a head $5 \mathrm{~cm}$ in width, and was placed immediately below the EMG sensors, placed parallel to the longitudinal axis of the muscle. From this perspective, and at a depth of $5.5 \mathrm{~cm}$, it was possible to obtain images to calculate both the pennation angle and the thickness of the ES. Figure 2 shows an example of a measure of this two muscle architectural variables (pennation angle and muscle thickness) from an ultrasound image. The ultrasonographer experience is higher than 5 years, ensuring proper collection of the ultrasound images.

For the analysis of all architectural variables, the clearest image was chosen to assure the right selection of the reference points of each measured parameter. Ultrasound is an instrument that has shown moderate to excellent reliability for the paraspinal musculature with intraclass correlation values ranging between 0.72 and 0.98 [25]. This tool has the disadvantage of relying on the skill of the operator when making a measurement. However, for the ES muscle, one study has shown that interobserver reliability ranged between 0.900 and 0.948 , while intraobserver values varied from 0.938 and 0.962 [7].

\section{Experimental protocol}

Before initiating the protocol for this study, participants filled out four questionnaires regarding their general health status (SF-12 (Short Form 12) [26,27], quality of life (EQ 5D (EuroQoL 5D) [28,29], level of disability (RMQ (Roland Morris Questionnaire) [30,31] and Orebro Musculoskeletal Pain Questionnaire (OMPQ) [32,33].

Figure 1 shows the schematic position of participants into pre-calibrated machine. Each subject made several attempts without charge to find the most comfortable position to developed the movement. Then the load cell mentioned previously record the torque of the isometric lumbar extension at 45 degrees from the vertical (90 degrees between hips and trunk flexion with the lumbar spine in neutral position). Two straps placed one on another in the hip and thigh, to ensure maintenance of the neutral position of the lumbar spine during movement execution. Before beginning the protocol, the correct subject position was confirmed using an electronic goniometer.

Each subject performed three thrusts during five seconds with a break of 90 seconds between trials. The peak force recorded was considered the maximum force that the participant could exert for that movement.

From this measurement as a reference, each subject then performed three isometric lumbar extensions for 5 seconds for each intensity: light (33\% MVC), moderate (66\% MVC) and maximal (100\% MVC) (9 repetitions in total). The rest between each repetition was 90 seconds.

During these measurements, electromyography recordings and ultrasound images bilaterally were and torque obtained following the methodology explained above. From the ultrasound images, the architectural variables (pennation angle and muscle thickness) were obtained while the EMG recording allowed for calculating the value of muscle activity during isometric contraction at 33\% (light), 66\% (moderate) and 100\% MVC (maximal voluntary contraction). The values of the $100 \%$ MVC were used to normalized the moderate and light isometric contractions.

Thus, the variables considered for analysis in this study were: Moderate contraction: pennation angle right side (AR Mod), pennation angle left side (AL Mod), muscle thickness right side (TR Mod), muscle thickness left side (TL Mod), muscle activation right side (EMG $\mathrm{R}$ Mod), muscle activation left side (EMG L Mod) and torque (Torque Mod). Light contraction: pennation angle right side (AR Light), pennation angle left side (AL Light), muscle thickness right side (TR Light), muscle thickness left side (TL Light), muscle activation right side (EMG $\mathrm{R}$ Light), muscle activation left side (EMG L Light) and torque (Torque Light).

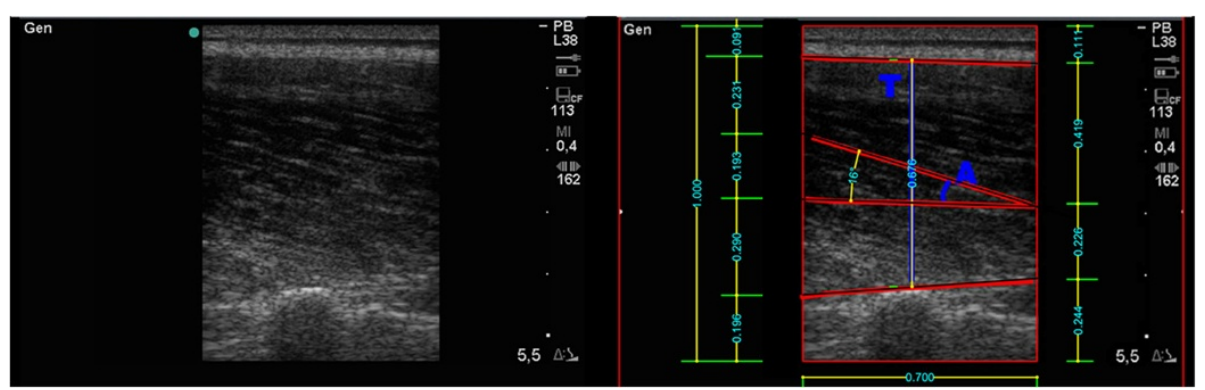

Figure 2 Example architecture variables measure from ultrasound image. A: Pennation Angle. T: Muscular Thickness. 


\section{Data analysis}

The average value of muscle activation and torque during relative isometric contractions (66\% and 33\%) were considered as the measure of these variables during each contraction. Muscle thickness and pennation angle were measured following an adapted procedure described by Hodges et al. [34]. Thickness was measured as the distance between the superficial and deep aponeuroses. Pennation angle was measured between a parallel aponeurosis line and the line of the clearest fascicle as the positive angle.

Data analysis was conducted in two parts. We performed a descriptive analysis of the results. The pool of data of EMG and US signals were normalized using package rank of free software R. Spearman bivariate correlation between architectural and functional variables of the ES muscle. These analyses were calculated using normalized data when performing moderate and light isometric lumbar extension. The interpretation of correlation coefficients used was: $r<0.49$, poor correlation, $0.50>\mathrm{r}<0.74$, moderate correlation, $\mathrm{r}>0.75$, strong correlation [35].

The Statistical Package for the Social Sciences (SPSS) (version 17.0 for Windows, Illinois, and USA) was used to perform data analysis.

\section{Results}

Table 1 shows the descriptive data of the sample obtained from subjective questionnaires. The results show the minimum, maximum, average and standard deviation of the characteristic of sample. Table 2 shows the values that describe the sample when they performed the tests at maximal, moderate and light intensities. It

Table 1 Descriptive statistics data obtained from subjective questionnaires

\begin{tabular}{lcccc}
\hline & Minimum & Maximum & Mean & SD. \\
\hline Age (years) & 22 & 50 & 30.39 & 7.79 \\
Weight (Kg) & 43 & 176 & 73.59 & 21.20 \\
Height (m) & 154 & 193 & 170.52 & 16.93 \\
BMI (Kg/m ${ }^{2}$ ) & 17.7 & 30.4 & 23.71 & 3.16 \\
EQ 5D & 0.61 & 1.00 & 0.92 & 0.10 \\
EQ VAS & 49 & 100 & 79.76 & 11.78 \\
SF-12 PCS & 22.81 & 65.96 & 51.77 & 8.93 \\
SF-12 MCS & 18.92 & 62.24 & 49.14 & 8.25 \\
OMPQ & 2 & 116 & 47.22 & 29.10 \\
RMQ & 0 & 9 & 1.43 & 2.33 \\
\hline
\end{tabular}

EQ 5D: EuroQoL 5 dimensions.

EQ VAS: EuroQoL VAS.

SF-12 PCS: Physical Component State.

SF-12 MCS: Mental Component State.

ÖMPQ: Örebro Musculoskeletal Pain Questionnaire.

RMQ. Roland Morris Questionnaire.
Table 2 Descriptive statistics data obtained from

functional tests

\begin{tabular}{|c|c|c|c|c|}
\hline $\begin{array}{l}\text { Functional and US } \\
\text { variables }\end{array}$ & 25 percentile & 75 percentile & Mean & SD \\
\hline Torque $100(\mathrm{~N} \cdot \mathrm{m})$ & 46.41 & 76.67 & 65.67 & 20.39 \\
\hline Torque 66 & 32.75 & 55.33 & 46.55 & 14.70 \\
\hline Torque 33 & 19.43 & 31.59 & 26.85 & 8.31 \\
\hline AR Max ( $\left.{ }^{\circ}\right)$ & 12.00 & 14.00 & 12.83 & 1.24 \\
\hline AR Mod & 8.52 & 9.79 & 9.15 & 0.93 \\
\hline AR Light & 4.93 & 5.85 & 5.39 & 0.60 \\
\hline AL Max & 12.00 & 14.00 & 12.83 & 1.24 \\
\hline AL Mod & 8.31 & 9.61 & 8.95 & 0.89 \\
\hline AL Light & 4.77 & 5.72 & 6.31 & 7.30 \\
\hline TR Max (mm) & 36.28 & 42.43 & 39.16 & 5.59 \\
\hline TR Mod & 26.74 & 31.18 & 29.18 & 4.18 \\
\hline TR Light & 17.81 & 21.78 & 19.91 & 2.87 \\
\hline TL Max & 35.63 & 45.38 & 40.27 & 6.73 \\
\hline TL Mod & 25.06 & 32.25 & 28.82 & 5.28 \\
\hline TL Light & 14.95 & 19.84 & 17.08 & 2.95 \\
\hline MVC R (mV) & 353.50 & 748.50 & 563.59 & 227.24 \\
\hline Mod VC R & 245.53 & 531.66 & 402.31 & 161.91 \\
\hline Mod Light R & 149.10 & 324.26 & 239.84 & 95.82 \\
\hline MVC L & 386.00 & 790.50 & 590.63 & 253.39 \\
\hline Mod VC L & 276.00 & 534.25 & 428.74 & 195.72 \\
\hline Mod Light L & 183.75 & 349.25 & 284.17 & 139.22 \\
\hline TR Mod Norm (\%) & 68.87 & 73.66 & 71.53 & 2.60 \\
\hline TL Mod Norm & 69.11 & 74.12 & 71.41 & 3.10 \\
\hline AR Angle Mod Norm & 69.07 & 73.86 & 71.359 & 2.65 \\
\hline AR Left Mod Norm & 67.48 & 71.69 & 69.79 & 2.61 \\
\hline Mod VC R Norm & 69.14 & 74.46 & 71.46 & 3.16 \\
\hline Mod VC L Norm & 68.28 & 73.33 & 71.18 & 2.67 \\
\hline Torque Mod Norm & 68.19 & 73.64 & 70.85 & 3.06 \\
\hline TR Light Norm & 40.17 & 44.10 & 42.08 & 2.50 \\
\hline TL Light Norm & 40.91 & 43.96 & 42.38 & 2.24 \\
\hline AR Angle Light Norm & 40.12 & 43.64 & 41.98 & 2.19 \\
\hline AR Left Light Norm & 39.70 & 42.26 & 41.09 & 1.92 \\
\hline Light VC R Norm & 40.94 & 43.95 & 42.65 & 2.26 \\
\hline Light VC L Norm & 41.81 & 44.35 & 42.77 & 1.95 \\
\hline Torque Light Norm & 39.15 & 43.20 & 41.15 & 2.37 \\
\hline
\end{tabular}

AR Max = Angle Right Maximum; AR Mod = Angle Right Moderate Intensity; AR low = Angle Right low Intensity; AL Max = Angle Left Maximum; AL Mod = Angle Left Moderate intensity; AL low = Angle Left low intensity; Thick R Max = Thickness Right Maximum; Thick R Mod = Thickness Right Moderate; Thick R low = Thickness Right low; Thick L Max = Thickness Left Maximum; Thick L Mod = Thickness Left Moderate; Thick L low = Thickness Left low; MVC $\mathrm{R}=$ Maximal; Voluntary Contraction Right; Mod VC R = Moderate Voluntary Contraction Right; Light VC R= low Voluntary Contraction Right; MVC $\mathrm{L}=$ Maximal Voluntary Contraction Left; Mod VC L = Moderate Voluntary Contraction Left; Light VC L = low Voluntary Contraction Left; Norm: Normalized values. 
shown absolute values for all intensities and normalized for moderate and light intensities, with the standard deviation and the 25 and 75 percentile. Considering that we investigated a group of young adult subjects whose anthropometric indices were normal for their perception of quality of life (EQ 5D and EQ VAS), general health (SF-12 physical component state and SF-12 mental component state), and level of musculoskeletal disabilities, both in general (OMPQ) and in the back region (RMQ).

Table 3 shows the relationship between the architectural and function variables. A strong significant correlation between data recorded for each intensity when the subjects performed moderate and light contraction were observed. Specifically, the correlation values observed during a moderate intensity range between 0.922 (AL Mod AR Mod) and 0.726 (Torque Mod - EMG L Mod). In turn, the correlations for a light intensity ranges from 0.923 (AL Light - AR Light) and 0.731 (EMG L Light - TR Light) (Table 3). However, the correlation between variables of different intensities shows a very poor value being the maximum value of -0.326 (AL Light - TL Mod).

\section{Discussion}

To our knowledge, this is the first study that has investigated the behaviour observed during isometric ES muscle contraction at different intensities followed by correlation analysis of the architectural and functional variables. Strong and moderate significant correlations were observed between the variables of the same intensities; however, the correlation between variables of different intensities was poor. While we have found strong correlations study on the architectural and functional variables of the ES during moderate and light lumbar isometric extension. Other trials have found a correlation in other trunk muscles $[11,12,35,36]$.

The observed correlations between variables of the same intensity are strong, showing values ranging from 0.726 (Torque Mod - Mod EMG L) and 0.923 (AL Light - Light AR). Furthermore, when the same variable correlated to each side at the same intensity, in any case, the correlation value never falls below 0.9. These values demonstrate a clear relationship between architectural change measures and functional activation measures for the ES when develop a lumbar isometric contraction at moderate and light intensities. These results are consistent with other studies that have indeed found significant correlations between these variables in the abdominal muscles. John and Beith [36] published a good correlation value for the EO (external oblique), presenting a range of correlation between 0.63 and 0.94 during isometric trunk rotation. In addition, Hodges et al. [34] showed a correlation index for transverse and IO (internal oblique) ranging between 0.84

Table 3 Correlation between architecture and functional variables

\begin{tabular}{|c|c|c|c|c|c|c|c|c|c|c|c|c|c|c|}
\hline & TR Mod & TL Mod & $\begin{array}{c}\text { AR } \\
\text { Mod }\end{array}$ & $\begin{array}{c}\text { AL } \\
\text { Mod }\end{array}$ & $\begin{array}{l}\text { EMG R } \\
\text { Mod }\end{array}$ & $\begin{array}{l}\text { EMG L } \\
\text { Mod }\end{array}$ & $\begin{array}{c}\text { Torque } \\
\text { Mod }\end{array}$ & $\begin{array}{c}\text { TR } \\
\text { Light }\end{array}$ & $\begin{array}{c}\text { TL } \\
\text { Light }\end{array}$ & $\begin{array}{c}\text { AR } \\
\text { Light }\end{array}$ & $\begin{array}{l}\text { AL } \\
\text { Light }\end{array}$ & $\begin{array}{c}\text { EMG R } \\
\text { Light }\end{array}$ & $\begin{array}{c}\text { EMG L } \\
\text { Light }\end{array}$ & $\begin{array}{c}\text { Torque } \\
\text { Light }\end{array}$ \\
\hline TR Mod & 1 & & & & & & & & & & & & & \\
\hline TL Mod & $0.917 \dagger$ & 1 & & & & & & & & & & & & \\
\hline AR Mod & $0.877 \dagger$ & $0.890+$ & 1 & & & & & & & & & & & \\
\hline AL Mod & $0.831 \dagger$ & $0.855+$ & $0.922 \dagger$ & 1 & & & & & & & & & & \\
\hline EMG R Mod & $0.897 \dagger$ & $0.907 \dagger$ & $0.876 \dagger$ & $0.839 \dagger$ & 1 & & & & & & & & & \\
\hline EMG L Mod & $0.825 \dagger$ & $0.900 \dagger$ & $0.812 \dagger$ & $0.776 t$ & $0.915 t$ & 1 & & & & & & & & \\
\hline Torque Mod & $0.884 \dagger$ & $0.826 t$ & $0.903 t$ & $0.858 \dagger$ & $0.816 \dagger$ & $0.726^{\dagger}$ & 1 & & & & & & & \\
\hline TR Light & -0.264 & $-0.303^{*}$ & $-0.315^{*}$ & -0.235 & -0.272 & -0.217 & -0.237 & 1 & & & & & & \\
\hline TL Light & -0.199 & -0.234 & -0.256 & -0.144 & -0.204 & -0.121 & -0.194 & $0.913 \dagger$ & 1 & & & & & \\
\hline AR Light & -0.237 & $-0.333^{*}$ & -0.280 & -0.165 & $-0.323^{*}$ & -0.246 & -0.189 & $0.779 \dagger$ & $0.863+$ & 1 & & & & \\
\hline AL Light & -0.251 & $-0.326^{*}$ & $-0.303^{*}$ & -0.204 & $-0.309^{*}$ & -0.213 & -0.205 & $0.776 \dagger$ & $0.851 \dagger$ & $0.923+$ & 1 & & & \\
\hline EMG R Light & -0.184 & -0.214 & -0.248 & -0.143 & -0.184 & -0.109 & -0.181 & $0.861 \dagger$ & $0.862 \dagger$ & $0.904 \dagger$ & $0.871 \dagger$ & 1 & & \\
\hline EMG L Light & -0.219 & -0.248 & $-0.314^{*}$ & -0.220 & -0.213 & -0.208 & -0.242 & $0.731 \dagger$ & $0.812 \dagger$ & $0.746 \dagger$ & $0.757 \dagger$ & $0.901 \dagger$ & 1 & \\
\hline Torque Light & -0.130 & -0.218 & -0.214 & -0.113 & -0.223 & -0.164 & -0.146 & $0.733 \dagger$ & $0.852 \dagger$ & $0.907 \dagger$ & $0.864 \dagger$ & $0.852 \dagger$ & $0.774 \dagger$ & 1 \\
\hline $\begin{array}{l}\text { T: thickness. } \\
\text { A: angle. } \\
\text { R: right. } \\
\text { L: left. } \\
\text { EMG: electromi } \\
\text { Mod: moderate } \\
\text { Significance lev } \\
{ }^{*}=0.05 . \\
\dagger=0.01 .\end{array}$ & $\begin{array}{l}\text { graphy. } \\
\text { el: }\end{array}$ & & & & & & & & & & & & & \\
\hline
\end{tabular}


and 0.90, but found no obvious correlation for EO. Brown et al. [12] who investigated three muscles that compose the abdominal wall (internal oblique (IO) and external oblique (EO) and transverse), did not found a clear correlation between the muscle activation degree and changes in the muscles during isometric positions for shortening of these muscles.

A study presented by Dickx et al. [17] noted, a strong relationship between the architectural changes observed in the ES and multifidus muscles, as measured by magnetic resonance imaging recording the level of muscle activation by EMG. The correlation coefficients were 0.957 for the multifidus and 0.887 for the ES. It is very interesting to analyze how the higher correlation values were observed between the variables describing the isometric contraction at the same intensity. These results may be due to the fact that all participants changed the variables studied when performing moderate and light contraction. However, the level of variation within subjects at each contraction intensity analyzed was differently.

One study measured the thickness of the ES [6] and presented a mean value of 39.4 $( \pm 4.2 \mathrm{~mm})$ [6]. These values were quite different to those observed during light contraction $(19.91 \pm 2.87$ and $17.08 \pm 2.95$, right and left, respectively). However, the values measured during moderate contraction $(29.18 \pm 4.18$ and $28.82 \pm 5.28$, right and left, respectively) were much closer to the average found in this study. This difference in the measures would be due to the difference in the position of the subject at the time when measurements were taken. While our study investigated at 90 degrees of hips flexion with lumbar spine in neutral position, Masuda's study [6] measured subjects at maximum extension. On the other hand, the muscle in our study was measured at maximal, moderate and light contraction, while in the study of Watanabe the muscle was measured in relaxation.

\section{Study limitation}

The ultrasound measurements have proven to be very reliable when it comes to being registered, but there is a small margin of error that must be taken within the totality of the results presented. It would also be advisable to conduct the same study in other positions and intensities of contraction, so as to increase the knowledge on the behaviour of a muscle so important for the statics and dynamics of the lumbar spine.

\section{Conclusion}

This study is the first to analysed the behaviour of the ES muscle from an architectural perspective while trying to find a functional relationship between the three variables considered (muscle thickness, pennation angle of the muscle fibres and muscle activation) during moderate and light isometric trunk and hip extension in a sitting position with hips flexed 90 degrees and the lumbar spine in neutral position.

It has been observed a strong correlation between the functional variables (EMG and torque) and architecture (pennation angle and muscle thickness) ES muscle when describing a moderate isometric lumbar extension and light. This strong correlation has been observed in the variables describing the gesture performed at the same intensity.

\section{Abbreviations}

ES: Erector spinae; LBP: Lowback pain; EMG: Electromyography; SF-12: Short form 12; EQ 5D: EuroQoL 5D; RMQ: Roland Morris Questionnarire;

OMPQ: Orebro musculoskeletal pain questionnaire; MVC: Maximal voluntary contraction; US: Ultrasound; SPSS: Statistical package for the social sciences; IO: Internal oblique; EO: External oblique.

\section{Competing interests}

The authors state that no conflicts of interest have been reported by the authors or by any individual in control of the content of this article. This information has not been presented previously.

\section{Authors' contributions}

Al C-V participated in the conception and design of the study, in the data collection, analysis and interpretation of data and helped to draft the manuscript. M G-S participated in the data collection, analysis and interpretation of data and drafted the manuscript. All authors read and approved the final manuscript.

\section{Authors' information}

Antonio I. Cuesta-Vargas is Senior Lecturer in the University of Malaga, Manuel González-Sánchez is a PhD Candidate in the university of Malaga.

\section{Acknowledgement}

I would like to thank all who took part in the intervention and enabled the study to take place.

Received: 27 November 2012 Accepted: 13 November 2013 Published: 19 November 2013

\section{References}

1. de Oliveira LF, Menegaldo LL: Individual-specific muscle maximum force estimation using ultrasound for ankle joint torque prediction using an EMG-driven Hill-type model. J Biomech 2010, 43(14):2816-2821.

2. Menegaldo $L L$, de Oliveira LF: Effect of muscle model parameter scaling for isometric plantar flexion torque prediction. J Biomech 2009, 42(15):2597-2601.

3. Kumar S: EMG in rotation-flexion of the torso. J Electromyogr Kinesiol 2010, 20(6):1146-1154

4. Sung PS, Lammers AR, Danial P: Different parts of erector spinae muscle fatigability in subjects with and without low back pain. Spine J 2009, 9(2):115-120.

5. Mannion AF, Dolan P: The effects of muscle length and force output on the EMG power spectrum of the erector spinae. J Electromyogr Kinesiol 1996, 6(3):159-168.

6. Masuda T, Miyamoto K, Oguri K, Matsuoka T, Shimizu K: Relationship between the thickness and hemodynamic of the erector spinae muscles in various lumbar curvatures. Clin Biomech (Bristol, Avon) 2005, 20(3):247-253.

7. Watanabe K, Miyamoto K, Masuda T, Shimizu K: Use of ultrasonography to evaluate thickness of the erector spinae muscle in maximum flexion and extension of the lumbar spine. Spine 2004, 29(13):1472-1477.

8. Guo JY, Zheng YP, Xie HB, Chen X: Continuous monitoring of electromyography (EMG), mechanomyography (MMG), sonomyography (SMG) and torque output during ramp and step isometric contractions. Med Eng Phys 2010, 32(9):1032-1042.

9. Li L, Tong $K$, Song R, Koo TK: Is maximum isometric muscle stress the same among prime elbow flexors? Clin Biomech (Bristol, Avon) 2007, 22(8):874-883. 
10. Manal K, Roberts DP, Buchanan TS: Can pennation angles be predicted from EMGs for the primary ankle plantar and dorsiflexors during isometric contractions? J Biomech 2008, 41(11):2492-2497.

11. Bland DC, Prosser LA, Bellini LA, Alter KE, Damiano DL: Tibialis anterior architecture, strength, and gait in individuals with cerebral palsy. Muscle Nerve 2011, 44(4):509-517.

12. Brown SH, McGill SM: A comparison of ultrasound and electromyography measures of force and activation to examine the mechanics of abdominal wall contraction. Clin Biomech (Bristol, Avon) 2010, 25(2):115-123.

13. McMeeken JM, Beith ID, Newham DJ, Milligan P, Critchley DJ: The relationship between EMG and change in thickness of transversus abdominis. Clin Biomech (Bristol, Avon) 2004, 19(4):337-342.

14. Rudroff T, Staudenmann D, Enoka RM: Electromyography measures of muscle activation and changes in muscle architecture of human elbow flexors during fatiguing contractions. J Appl Physiol 2008, 104(6):1720-1726.

15. Maganaris CN, Baltzopoulos V: Predictability of in vivo changes in pennation angle of human tibialis anterior muscle from rest to maximum isometric dorsiflexion. Eur J Appl Physiol Occup Physiol 1999, 79(3):294-297.

16. Jhu JL, Chai HM, Jan MH, Wang CL, Shau YW, Wang SF: Reliability and relationship between 2 measurements of transversus abdominis dimension taken during an abdominal drawing-in maneuver using a novel approach of ultrasound imaging. J Orthop Sports Phys Ther 2010, 40(12):826-832.

17. Dickx N, D'Hooge R, Cagnie B, Deschepper E, Verstraete K, Danneels L: Magnetic resonance imaging and electromyography to measure lumbar back muscle activity. Spine (Phila Pa 1976) 2010, 35(17):E836-E842.

18. Humphrey AR, Nargol AV, Jones AP, Ratcliffe AA, Greenough CG: The value of electromyography of the lumbar paraspinal muscles in discriminating between chronic-low-back-pain sufferers and normal subjects. Eur Spine $J$ 2005, 14(2):175-184

19. Shi J, Zheng YP, Huang QH, Chen X: Continuous monitoring of sonomyography, electromyography and torque generated by normal upper arm muscles during isometric contraction: sonomyography assessment for arm muscles. IEEE Trans Biomed Eng 2008, 55(3):1191-1198.

20. Bogduk N, Macintosh JE, Pearcy MJ: A universal model of the lumbar back muscles in the upright position. Spine 1992, 17:897-913.

21. Bogduk N: The lumbar disc and low back pain. Neurosurg Clin N Am 1991, 2:791-806.

22. McGill SM, Norman RW: Partitioning of the L4-L5 dynamic moment into disc, ligamentous, and muscular components during lifting. Spine 1986, 11:666-678.

23. Sánchez-Zuriaga D, Adams MA, Dolan P: Is activation of the back muscles impaired by creep or muscle fatigue? Spine 2010, 35(5):517-525

24. Declaracion de Helsinki de la AMM: Principios éticos para las investigaciones médicas en seres humanos. http://www.uma.net/es/30publications/ 10policies/b3/index.html]. Accessed cited 2011 April 22.

25. Stokes M, Hides J, Elliott J, Kiesel K, Hodges P: Rehabilitative ultrasound imaging of the posterior paraspinal muscles. J Orthop Sports Phys Ther 2007, 37(10):581-595.

26. Luo X, Lynn George M, Kakouras I, Edwards C, Pietrobon R, Richardson W: Rieability, validity and responsiveness of the short form 12-item survey (SF-12) in patients with back pain. Spine 2003, 1:1739-1745.

27. Ware JE, Kosinski M, Keller SD: SF-12: How to Score the SF-12 Physical and Mental Health Summary Scales. 2nd edition. Boston, MA: The Health Institute, New England Medical Center; 1995.

28. Badía X, Roset M, Montserrat S, Herdman M, Segura A: The Spanish version of EuroQol: a description and its applications. European Quality of Life scale. MedClin (Barc) 1999, 112:79-85.

29. Van Agt HM, Essink-Bot ML, Krabbe PF, Bonsel GJ: Test-retest reliability of health state valuations collected with the Euro Qol questionnaire. Soc Sci Med 1994, 39:1537-1544

30. Roland M, Morris R: A study of the natural history of back pain: Part I. Development of a reliable and sensitive measure of disability in lowback pain. Spine 1983, 8:141-144.

31. Roland M, Morris R: A study of the natural history of low-back pain: Part II. Development of guidelines for trials of treatment in primary care. Spine 1983, 8:145-150.

32. Linton SJ, Halldén K: Can we screen for problematic back pain? A screening questionnaire for predicting outcome in acute and subacute back pain. Clin J Pain 1998, 14(3):209-215.
33. Gabel CP, Melloh M, Yelland M, Burkett B, Roiko A: Predictive ability of a modified Orebro Musculoskeletal Pain Questionnaire in an acute/subacute low back pain working population. Eur Spine J 2011, 20(3):449-457.

34. Hodges PW, Pengel LHM, Herbert RD, Gandevia SC: Measurement of muscle contraction with ultrasound imaging. Muscle Nerve 2003, 27:682-692.

35. Portney LG, Watkins MP: Foundations of Clinical Research. Applications to Practice, Volume 2. Prentice Hall Health: Upper Saddle River, NJ; 2000.

36. John EK, Beith ID: Can activity within the external abdominal oblique be measured using real-time ultrasound imaging? Clin Biomech 2007, 22:972-979

doi:10.1186/1471-2342-13-38

Cite this article as: Cuesta-Vargas and Gonzalez-Sanchez: Relationship of moderate and low isometric lumbar extension through architectural and muscular activity variables: a cross sectional study. BMC Medical Imaging 2013 13:38.

\section{Submit your next manuscript to BioMed Central and take full advantage of:}

- Convenient online submission

- Thorough peer review

- No space constraints or color figure charges

- Immediate publication on acceptance

- Inclusion in PubMed, CAS, Scopus and Google Scholar

- Research which is freely available for redistribution

Submit your manuscript at www.biomedcentral.com/submit
C Biomed Central 